\title{
EL DELITO DE OMISIÓN DE SOCORRO EN EL ÁMBITO SANITARIO
}

\author{
MANUEL ARAUZ ULLOA \\ Prof. Adjunto de Derecho Penal \\ Decano de la Facultad de Ciencias Juridicas (UCA)
}

Q

ué responsabilidad penal podríamos imputar a un médico o al personal sanitario que, viendo que el paciente llega a la Sala de Emergencia padeciendo

una herida o una dolencia grave, omiten displicentemente, con pleno conocimiento, prestarle los servicios médicos necesarios, omisión producto de la cual resulta la muerte o la producción de daños en la salud que bien pudieron ser evitados con la atención debida.

La misma situación se pudiera presentar en aquellos casos en los que el personal médico, por razones de conciencia (caso del aborto p.ej.), por razones administrativas (el paciente no está asegurado, o su previsional lo tiene contratado en otro centro) e incluso por razones económicas, omiten cualquier atención con las consecuencias del caso.

Si bien en nuestra legislación sólo podríamos recurrir a las figuras de exposición de personas al peligro (art. $154 \mathrm{Pn}$ ) y a la técnicamente discutible construcción de un delito de homicidio o lesiones en comisión por omisión, algunas legislaciones en el ámbito del Derecho Comparado ya han resuelto la cuestión, un ejemplo de ello es el artículo 196 del Código Penal español de 1995.

Art. 196.

"El profesional que, estando obligado a ello, denegare asistencia sanitaria o abandonare los servicios sanitarios, cuando de la denegación o abandono se derive riesgo grave para la salud de las personas, será castigado con las penas del artículo precedente en su mitad superior y con la de inhabilitación especial para empleo o cargo público, profesión u oficio, por tiempo de seis meses a tres años".

\section{Introducción}

Es opinión generalizada en la doctrina española que el artículo $196 \mathrm{CP}$ constituye una verdadera novedad pues no existen precedentes que muestren un tipo penal de 
tal naturaleza en los Códigos penales anteriores al de $1995^{\circ}$. Quizá algún antecedente podría extraerse del art. 585 CP de 1822 que establecía la obligación de médicos, cirujanos, comadrón, matronas, sangradores o barberos a acudir ante el requerimiento de la autoridad para realizar algún reconocimiento o curación, en definitiva, para prestar las asistencias o auxilios propios de su arte ${ }^{2}$; no obstante, como ya señalara ALAMILLO CANILLAS, la estructura del delito respondía más a un delito de desobediencia que a un delito de omisión del deber de socorro ${ }^{3}$. Se impone pues preguntarnos si antes del CP de 1995 las conductas de omisión de asistencia por parte del personal médico sanitario eran impunes o, por el contrario, se castigaban a través del delito de omisión del deber de socorro o por otro tipo penal. Los antecedentes jurisprudenciales demuestran que estas conductas, lejos de quedar impunes se sancionaban por distintas vías ${ }^{4}$ : algunas veces, aplicando el art. 489 bis CP 1944/1973; otras, a través de la falta del art. 586, 2. ${ }^{\circ}$ del mismo Código y, cuando el médico ostentaba el carácter de funcionario público, se aplicaba el art. 371. 3० CP 1944/19735.

Entre otros, GOMEZ PAVÓN, PJ 40, 1995, 287; CARBONELL MATEU/GONZÁLEZ CUSSAC en: Vives Antón (coord.), Comentarios 1, 1996, 988; Vives Antón y otros, DP PE, 3.a, 1999, 280; GOMEZ RIVERO, LL 1996-3, 1386; MORA ALARCÓN, Suma PG y E, 1996, 374; PORTILLA CONTRERAS en: Cobo Del Rosal (dir.), Curso PE 1, 1996, 385; QUERALT JIMENEZ, DP PE, 3.a, 1996, 176, expresando que la introducción de este nuevo art. no era necesaria; ALMELA VICH, PJ 48, 1997, 252; COBOS GOMEZ DE LINARES en: Rodríguez Ramos/Cobos Gómez/Sánchez Tomás, DP PE II, 1997, 23; GÓMEZ PAVÓN, Tratamientos médicos, 1997, 301; HUERTA TOCILDO, Principales novedades, 1997, 14; RODRIGUEZ MOURULLO en: Rodríguez Mourullo (dir.), Comentarios, 1997, 559; MOLINA FERNÁNDEZ en: Bajo Fernández (dir.), Compendio PE II, 1998, 177; FARALDO CABANA, PJ 55, 1999, 49; GARCLA ALBERO en: Quintero Olivares (dir.), Comentarios PE, 2.a 1999, 321; MUNOZ CONDE, DP PE, 12." , 1999, 312.

2 Art. 585. "El médico, cirujano, comadrón, matrona, boticario, sangrador o barbero que llamados y requeridos por autoridad competente para hacer algún reconocimiento o curación o para prestar la asistencia o los auxilios propios de su arte rehusaren desempeñar este servicio, sin causa legitima que lo impida, podrán ser arrestados en el acto por cuatro a quince dias, pagarán una multa de dos a diez duros $y$, sin perjuicio de ser compelidos a obedecer lo que se les hubiere mandado, serán suspensos del ejercicio de su profesión por uno a seis meses. Pero si cometieren este delito en el caso de no haber en el pueblo otro facultativo que pueda suplir sus veces, o en el de que aún cuando lo haya no dé la urgencia lugar a dilación, y resultare efectivamente de la desobediencia un perjuicio de consideración contra alguna persona o contra la administración de justicia, será la pena de dos meses a un año de reclusión, con una multa de diez a cincuenta duros y suspensión de la profesión por un año más".

3 ALAMILLO CANILLAS, La solidaridad, 1962, 52; con referencias del Derecho comparado (tanto de Europa como de Hispanoamérica), MARTÍNEZ-PEREDA RODRfGUEZ, La responsabilidad penal, $3 . \mathrm{a}, 1997,386$ ss.; APen 1997-2, 919 ss.

4 De ellas nos hablan, entre otros, Del ROSAL, RGLJ 211, 1961, 393 s.; ROMEO CASABONA, APen 1993-2, 461 s.; PORTIlla CONTRERAS en: Cobo Del Rosal (dir.), Curso PE I, 1996, 385 s.; HUERTA TOCILDO, Principales novedades, 1997, $57 \mathrm{~s}$, añadiendo que el abanico de opciones punitivas existente no resultaba, sin embargo, ni suficiente ni satisfactorio; en el mismo sentido, MARTÍNEZPEREDA RODRfGUEZ, La responsabilidad penal, 3. ${ }^{2}$, 1997, 398 s.; APen 1997-2, 922 s.; GARCLA ALBERO en: Quintero Olivares (dir.), Comentarios PE, 2. ${ }^{a}, 1999,321$. En la doctrina italiana, respecto de la subsunción de estas conductas en el delito de omisión de socorro (art. $593 \mathrm{CP}$ ) o en el de omisión de actos de despacho propios de los funcionarios públicos (art. $328 \mathrm{CP}$ ); GUARNERI, Il delitto di omissione, 1937, 118 s., n. 1; PANNAIN, NDI XI, 3.", 1957, 903; CHIODI, RItML 1980, 264; IADECOLA, RItML 1986, 54 s.; GP 1989, 126 s.; BONELLI/GIANNELLI, RItML 1992, 776 s.

5 Dejamos de lado los casos en los que la jurisprudencia y algún sector doctrinal subsumen estos supuestos dentro de los delitos de comisión por omisión; al respecto se pueden consultar los trabajos de SILVA SÁNCHEZ, LL 1987-1, 955 ss.; tb. en: Mir Puig (edit.), Avances, 1988, 125 ss.; ROMEO CASABONA, APen 1993-2, 461 ss.; SOLA/HERNANDEZ/ROMEO en: Romeo Casabona (edit.), Responsabilidad penal, 1993, 101; JORGE BARREIRO, CuadDJ XXIII, 1994, 238 ss. 
En el primer supuesto, omisión del deber de socorro del art. 489 bis, se sitúan las SSTS de 25 de enero de 1958 y 19 de diciembre de $1981^{6}$; la primera confirmó la sentencia que condenaba como autor del delito de omisión del deber de socorro al médico que, habiendo sido requerido por los familiares de la persona en peligro (niña de corta edad), se negó a prestar la asistencia solicitada, "desconociendo no sólo los principios de una depurada ética ciudadana, sino también los deberes profesionales o sociales especialmente exigibles al remiso, y se manifiesta con singular relieve cuando el hecho se contrae a la negativa opuesta por un médico"7. La segunda sentencia aborda el caso de un médico ginecólogo que estando de guardia en el Hospital Civil de Málaga se negó a prestar la asistencia facultativa que le fue requerida para una parturienta que se encontraba en trance de alumbramiento anormal, faltando de esta manera "al deber de cooperación y ayuda al semejante impuesto por la ley a todo ciudadano y mucho más a quienes, como él, están llamados, por su profesión, a procurar el remedio de las dolencias humanas y la curación y alivio de las aflicciones corporales" $"$.

En el segundo supuesto, falta del art. $5862 .^{\circ}$ (omisión de socorro a requerimiento de un tercero), se sitúa la STS de 20 de abril de $1964^{\circ}$ que, reformando la sentencia de instancia, condenó como autor de la falta del art. 5862. ${ }^{\circ} \mathrm{CP} 1944$ al médico traumatólogo que se negó a atender a un herido en accidente que llevaron hasta la Clínica donde él actuaba $^{10}$. Finalmente, y como supuesto tercero, se encuentran las sentencias que, teniendo en cuenta el carácter de funcionario público del médico, aplicaban el art. 371. 3. ${ }^{\circ}$ CP 1944/1973 (omisión de auxilio por parte de funcionario público)" ${ }^{11}$ así la STS

${ }^{6}$ STS 25 enero 1958 (A 70) y STS 19 diciembre 1981 (A 5095) respectivamente.

7 Una resolución similar del BGH, aunque llegando a distinto resultado (homicidio imprudente en comisión por omisión), es la recogida por VICTOR GULLCO (DocP 37, 1987, 53 s); valga decir que este autor manifiesta su discrepancia con la sentencia, dudando incluso que la conducta encuadre en el delito de omisión de auxilio del CP argentino. Examinando pronunciamientos similares en la jurisprudencia italiana, ALIBRANDI, RivPen 1974, 400 s.; CHIODI, RItML 1980, 254 ss.; BONELLI/GIANNELLI, RItML 1992, 777 ss.

8 Añadimos que en ambos casos se produjo la muerte de las víctimas (de la niña en el primer caso y del feto en el segundo), aunque a efectos del delito de omisión del deber de socorro, como delito de omisión pura, tal resultado no tenga trascendencia. Pero es destacable que dichas STS no castigan por homicidio -ni doloso ni imprudente- en comisión por omisión.

"STS 20 abril 1964 (A 2227).

10 Al margen de la idea que en el texto queremos trasladar, parece un poco benévola la calificación hecha por el TS, toda vez que el relato de los hechos probados inducía a una calificación más grave tal y como lo solicitaba el Ministerio Fiscal.

$"$ Sobre los requisitos de este art. 371. 3. nos ilustra la STS 16 febrero 1996 (A 883), señalando que el delito se integra por la concurrencia de los siguientes elementos: Primero, tener el agente la condición de funcionario público; segundo, que un particular le requiera para prestar algún auxilio; tercero, que el requerido esté obligado a prestarlo por razón de su cargo; cuarto, que el auxilio se requiera para evitar un delito o cualquier otro mal; quinto, que el agente se abstuviese de prestarlo sin causa que justifique la abstención. Más detalles en el comentario que sobre la misma sentencia realiza GONZÁLVEZ AGUADO, RC, sep., 1996, 521 ss. 
de 28 de enero de $1961^{12}$, STS de 7 de diciembre de $1973^{13}$, STS de 21 de junio de $1989^{14}$, STS de 2 de octubre de $1989^{15}$ y STS de 16 de febrero de $1996^{16}$, remarcando en todas ellas que el art. $371.3 .^{\circ}$ es de aplicación especial respecto del genérico delito de omisión del deber de socorro por dos razones: la primera, porque en los casos enjuiciados el médico que ha omitido el socorro ostentaba el carácter de funcionario público y, la segunda, porque como tales "es de plena ortodoxia moral y legal que les alcance un plus de exigibilidad en el cumplimiento de sus deberes específicos, y consecuentemente un plus de responsabilidad en sus omisiones y abstenciones en la prestación del auxilio"17, puesto que como miembros de la profesión médica tienen mayores posibilidades de brindar un socorro eficaz, de ahí que su omisión "vulnere el deber específico y personal de cooperación que le viene impuesto por razón de su cargo con la finalidad de prevenir y, en la medida de lo posible, evitar o reparar determinados males"18.

Sobre la aplicación de estos tipos penales la doctrina más autorizada ha cuestionado su utilización en los casos de omisión de asistencia sanitaria; en primer lugar, porque con el art. 489 bis el castigo de la conducta abstencionista del médico no podía ser distinto ni ir más allá de la pena establecida para un ciudadano normal, es decir, para una persona que no tenía las cualidades del médico ${ }^{19}$; en segundo lugar, porque sancionar conforme a la falta del art. 586, 2. ${ }^{\circ} \mathrm{CP} 1944 / 1973$, además de contener una pena muy leve, parecía incapaz de abarcar todo el desvalor de la conducta y, en tercer lugar, porque el castigo por medio del art. $371.30^{\circ}$ tenía como inconveniente que no podía ser aplicado a aquellos casos en que el médico -por ejercer libremente su profesión-, o cualquier otro miembro de un cuerpo sanitario, no tuviese la cualidad

${ }_{12}$ (A 81 )

13 (A 4937).

${ }^{14}$ (A 5187).

is (A 7538).

16. (A 883)

17 STS 7 diciembre 1973 (A 4937); STS 2 octubre 1989 (A 7538).

${ }^{18}$ STS 16 febrero 1996 (A 883).

19 Así Del ROSAL (RGLJ 1961, 396 ss.) exponía que en estos casos el planteamiento debería encajarse por el lado de simple persona, pues si se toma en cuenta la cualidad del omirente con el fin de subsumir la conducta en un tipo penal concreto, no podría castigarse por ninguno de los dos preceptos (489 bis y 586 2. ${ }^{\circ}$ CP 1944); en la misma línea se sitúa la STS 18 enero 1966 (A 106), cuando afirma: "que el precepto del párrafo $1 .^{\circ}$ del art. 489 bis no fue incorporado al referido Código para sancionar con penas la mayor o menor impericia de los profesionales de la Medicina, sino para castigar adecuadamente el voluntario incumplimiento del deber general de asistencia inherente a la solidaridad humana, en cuanto integra el mínimo moral exigible a los hombres para una ordenada existencia social". 
de funcionario público ${ }^{20}$, en cuyo caso se hacía necesario recurrir nuevamente al delito de omisión de socorro, siempre que concurriesen todos los elementos típicos ${ }^{21}$. Como consecuencia de lo anterior, la doctrina penal comenzó a reclamar el establecimiento de un tipo penal capaz de abarcar todas estas situaciones, un tipo penal en el que pudieran aglutinarse, por un lado, el desvalor de la omisión de asistencia cometida por un profesional del ámbito sanitario y, por otro, la posibilidad de sancionar estos supuestos con una pena superior a la prevista por el delito de omisión del deber de socorro ${ }^{22}$; en definitiva, se requería un tipo penal que, tomando en cuenta estas circunstancias, funcionara -como ya lo propusiera SILVA SÁNCHEZ- como una tercera vía entre la omisión de socorro y los casos que -por ser equivalentes a la comisión activa-, fundamentan un delito en comisión por omisión ${ }^{23}$, un tipo penal que, al mismo tiempo, contribuyera a solucionar la vieja problemática que los supuestos del médico rural y del médico de guardia plantean, es decir, con SILVA, aquellos casos de "posición de monopolio de ayuda" que tantos problemas han causado a la doctrin ${ }^{24}$.

Es evidente que las alternativas de solución contenidas en el CP 1944/1973 (arts. 489 bis, 586. 2..$^{\circ}$ y $371.3^{\circ}$ ) no consumían todo desvalor de una omisión de auxilio cometida por un profesional del ámbito sanitario, ni daban justa solución a los casos más problemáticos del médico rural y del médico de guardia a quienes -con excepción del art. $371.3^{\circ}$ que se aplica a los que ostentaban el carácter de funcionarios públicosse les sancionaba en idéntica medida a la sanción que se aplicaba a cualquier otro ciudadano; esta situación es la que dio lugar al delito de omisión de asistencia sanitaria contenido en el artículo 196 del CP 1995.

En líneas generales, los diferentes criterios interpretativos que sobre este delito ha expuesto la doctrina más reciente abordan una problemática que se proyecta en distintas direcciones, tales como concretar su naturaleza, determinar si se trata de un tipo agravado o, por el contrario, es un tipo autónomo e independiente del delito de omisión del deber de socorro genérico, para ocuparse luego del bien jurídico protegido, de la conducta típica $y$, finalmente, de los sujetos que intervienen y de la parte subjetiva del tipo.

20 Además, podemos añadir el inconveniente apuntado por SILVA SÁNCHEZ [LL 1987-1, 961, n. 53; tb. en: Mir Puig (edit.), Avances, 1988, 136 s., n. 53] al señalar que en el delito de denegación de auxilio la conducta abstencionista del médico lo que lesiona es el bien jurídico "correcto funcionamiento de los órganos de la Administración Pública", con lo que el delito en cuestión se aleja cada vez más del ámbito de la solidaridad humana concretada sobre los bienes jurídicos vida e integridad física.

21 Al respecto, ROMEO CASABONA, APen 1993-2, 462.

22 Por todos, HUERTA TOCILDO, Principales novedades, 1997, 59.

23 SILVA SÁNCHEZ, El delito de omisión, 1986, 343 ss.; LL 1987-1, 958; tb. en: Mir Puig (edit.), Avances, 1988, 132, proponiendo de lege ferenda, como ya lo haría en otros trabajos, la tipificación de omisiones de gravedad intermedia, en su denominación "omisiones puras de garante"; JORGE BARREIRO, CuadDJ XXIII, 1994, 238 ss., recogiendo los planteamientos de Silva Sánchez.

24 Vid. SILVA SÁNCHEZ, LL 1987-1, 958; tb. en: Mir Puig (edit.), Avances, 1988, 130; GOMEZ PAVON, PJ 40, 1995, 293; tb. en: Tratamientos médicos, 1997, 307. En la doctrina italiana, BONELLI/ GIANNELLI, RITML 1992, 771 ss. 


\section{Naturaleza}

En lo que concierne a la naturaleza del delito debemos decir que existen diversas opiniones al respecto: así mientras unos hablan de un delito de omisión pura, simple actividad y de peligro concreto ${ }^{25}$, otros, que representan la posición más extendida en la doctrina, lo consideran como una categoría de los denominados delitos de omisión y resultado y en otros casos, como una expresión de los llamados delitos de omisión pura de garante ${ }^{26}$.

\section{Quienes como ALMELA VICH ${ }^{27}$, GARCÍA ALBERO ${ }^{28}$ y GÓMEZ PAVÓN (esta} última inicialmente $\left.{ }^{29}\right)$ entienden que estamos ante un delito de los llamados de "omisión pura de garante", basan su posición en que el tipo penal del art. 196 no se conforma con la mera omisión del deber jurídico, sino que es necesario que de la denegación o abandono se produzca un riesgo grave para la salud de las personas, pues el legislador penal no desvalora penalmente toda denegación o abandono, sino sólo aquellas que representan un riesgo grave para la salud de personas determinadas, y de esta manera la figura delictiva en cuestión se sitúa a mitad de camino entre las omisiones puras y los delitos de comisión por omisión, constituyendo un "tertium genus" con peculiaridades propias, es lo que SILVA SÁNCHEZ ha llamado, omisiones puras de garante $^{30}$. A la opinión anterior debemos añadir la posición de LÓPEZ BARJA DE

25 Al respecto, CARBONELL MATEU/GONZÁLEZ CUSSAC en: Vives Antón (coord.), Comentarios I, 1996, 988; Vives Antón y otros, DP PE, 3.a, 1999, 280 s.; GÓMEZ RIVERO, LL 1996-3, 1387; LANDECHO VELASCO/MOLINA BLÁZQUEZ, DP PE, 2. ${ }^{\mathrm{a}}, 1996,141$; PORTILLA CONTRERAS en: Cobo Del Rosal (dir.), Curso PE I, 1996, 388; QUERALT JIMÉNEZ, DP PE, 3.a, 1996, $176 \mathrm{~s}$, (advertimos que en un primer momento y de entrada lo califica como un delito de peligro abstracto, luego lo sitúa dentro de los delitos de peligro concreto, para luego decir que si observamos detenidamente nos encontramos ante un delito de comisión por omisión); COBOS GÓMEZ DE LINARES en: Rodríguez Ramos/Cobos Gómez/Sánchez Tomás, DP PE II, 1997, 23.

26 Sobre esta tipología intermedia cfr. SILVA SÁNCHEZ, El delito de omisión, 1986, 343 ss.; LL 1987-1, 958; tb. en: Mir Puig (edit.), Avances, 1988, 132.

${ }^{27}$ ALMELA VICH, PJ 48, 1997, 252.

28 GARCfA ALBERO en: Quintero Olivares (dir.), Comentarios PE, 2.a 1999, 321.

29. Pues en una segunda opinión mantiene que la figura contenida en el art. 196 debía calificarse como un delito de comisión por omisión de peligro concreto, en cuanto es necesario que la misma "provoque" un riesgo para la salud, cfr. GOMEZ PAVÓN, PJ 40, 1995, 293 y 295; Tratamientos médicos, 1997, 308 y 309.

30) En relación con ia terminología utilizada por SILVA SANCHEZ, cfr, El delito de omisión, 1986, 339 s.; LL 1987-1, 960; tb. en: Mir Puig (edit.), Avances, 1988, 133 s.; CPC 38, 1989, 369, n. 7; El nuevo Código penal, 1997, 70 s. Sobre la construcción del texro vid., GOMEZ PAVÓN, PJ 40, 1995, 289; Tratamientos médicos, 1997, 303; ALMELA VICH, PJ 48, 1997, 252; GARClA ALBERO en: Quintero Olivares (dir.), Comentarios PE, 2. ${ }^{2}, 1999,321$. Tb. habla de este tipo de omisiones de gravedad intermedia MARTÍNEZ-PEREDA RODRIGUEZ, APen 1997-2, 921, aunque antes (918) lo había clasificado como un delito de omisión y resultado -de peligro-, luego en páginas posteriores (926) expresa que se trata de un delito de omisión propia, simple actividad y de peligro concreto. En contra de que se considere a este tipo penal como un delito de omisión pura de garante, FARALDO CABANA, PJ 55, 1999, $53 \mathrm{~s}$. 
QUIROGA y PÉREZ DEL VALLE31, para quienes el art. 196 establece una "posición de garante" de evitación de resultados de peligro concreto, que no se limita al médico, sino que, se extiende a otros profesionales de la actividad sanitaria; para los mencionados autores, este tipo penal es aplicable sólo de forma subsidiaria a los garantes de evitación de resultados cuando el resultado de lesión no se ha producido o no es imputable al garante, ya que si se produce el resultado de lesión y éste es imputable al garante, caeríamos en la esfera del art. $11 \mathrm{CP}$, es decir, estaríamos ante un delito de homicidio o lesiones en comisión por omisión, y ello porque el art. 196 lo que trata de evitar es la producción de un resultado de peligro concreto, se trata pues, de un delito de omisión enlazado con un delito de peligro concreto que funciona como resultado ${ }^{32}{ }^{33}$. Si esto es así, y al delito de omisión que venimos tratando se le asocia un resultado (de peligro concreto), entonces ya no estamos ante un delito de omisión pura propiamente dicho, y tampoco ante los llamados por SILVA SÁNCHEZ "delitos de omisión pura de garante" 34 ; más bien encaja en la primera modalidad de las llamadas por él "omisiones referidas a resultado" 35 , constituida por aquellas omisiones que, apareciendo expresamente tipificadas en preceptos de descripción negativa y siéndoles imputado un resultado, carecen sin embargo de una paralela realización comisiva de la que puedan considerarse equivalentes; son, utilizando la denominación acuñada por SILVA, omisiones referidas a resultado sin equivalencia comisiva, oponibles a aquellas realizaciones típicas omisivas referidas a resultado que muestran equivalencia con la correspondiente comisión activa, en cuanto puede imputárseles el resultado en idéntica medida que a la creación activa de riesgo de

31 LOPEZ BARJA DE QUIROGA/PÉREZ DEL VALLE en: Conde-Pumpido Ferreiro (dir.), Código penal II, 1997, 2307.

32 LÓPEZ BARJA DE QUIROGA/PÉREZ DEL VALLE en: Conde-Pumpido Ferreiro (dir.), Código penal II, 1997, 2307 (cursivas añadidas); LOPEZ BARJA DE QUIROGA en: Granados Pérez/López Barja, Contestaciones PE II, 1998, $151 \mathrm{~s}$.

33 Sobre el concepro de peligro concreto, sea como elemento de cualificación de algunos delitos, sea como resultado típico de otros cfr. RODRIGUEZ MONTAÑÉS, Delitos de peligro, 1994, 37 s., y 150 ss.; tb. MÉNDEZ RODRÍGUEZ, Los delitos de peligro, 1993, en esp. 211 ss.

34 La misma opinión mantiene HUERTA TOCILDO, Principales novedades, 1997, 69.

35 Caracterizadas por la posibilidad de serles imputable un resultado trascendente a la no-realización de la conducta indicada y que, a consecuencia de este hecho, no ha sido evitado por el sujeto; también tienen como característica común el estar fundadas en la existencia de una base funcional específica, la concurrencia, en todo caso, de un círculo restringido de sujetos que son los únicos que pueden realizarlas, y por último, desde el punto de vista valorativo, el tratarse de hechos más graves, en similares circunstancias, que los contemplados en la clase de las omisiones puras. De este tipo de omisiones se puede hacer una clasificación tripartita así: primera, omisiones referidas a resultado sin equivalencia comisiva (sin 'Begehungsgleichheit'); segunda, omisiones con equivalencia comisiva legalmente determinada (con 'Begehungsgleichheit'); y tercera, omisiones con equivalencia comisiva legalmente indeterminadas (comisión por omisión). Cfr. SILVA SÁNCHEZ, El delito de omisión, 1986, 347 ss.; expresamente en: Cobo del Rosal (dir.), Comentarios I, 1999, 469; tb. nos hablan de esta categoría de "delito de omisión y resultado", RODRIGUEZ MOURULLO, La omisión de socorro, 1966, 77; NOVOA MONREAL, Fundamentos, 1984, 122 ss. 
producción del mismo ${ }^{36}$. Parcialmente coincidente con la posición anterior se muestra la postura de HUERTA TOCILDO, para quien el delito del art. $196 \mathrm{CP}$ comporta un delito de omisión y resultado, que como modalidad de los delitos de comisión por omisión debe necesariamente asociarse a él un determinado resultado, en este caso, de peligro concreto, adelantando de esta manera las barreras de protección penal al momento de la aparición de dicho peligro, sin que sea necesario esperar a que se produzca la efectiva lesión del bien jurídico ${ }^{37}$.

\section{III. ¿Tipo Agravado o Autónomo?}

Tomando como premisa que el legislador penal de 1995 ha ubicado este delito dentro del Tít. IX dedicado a la omisión del deber de socorro y ha subordinado la pena al marco de referencia establecido por el art. 195, la doctrina discute si la figura contenida en el art. 196 es una modalidad agravada del delito de omisión del deber de socorro o, por el contrario, constituye un tipo autónomo e independiente.

Para algunos autores se trata de un tipo agravado del genérico delito de omisión del deber de socorro ${ }^{38}$, no sólo por encontrarse dentro del mismo título, sino porque además el legislador ha subordinado la pena del art. 196 al marco de referencia establecida por el art. 195; lo que no dejan claro estos autores es si en el tipo agravado deben necesariamente concurrir los requisitos del tipo básico, es decir, que la persona esté desamparada y en peligro manifiesto y grave.

Otros autores, en cambio, opinan que no se trata de una modalidad agravada del art. 195, aunque frecuentemente concurran en un mismo caso ambas figuras típicas; de

36 Cfr. SILVA SÁNCHEZ, El delito de omisión, 1986, 343-349; El nuevo Código penal, 1997, 73, calificando el tipo penal como constitutivo de un delito de omisión y resultado -de peligro-; MARTÍNEZPEREDA RODRIGUEZ, APen 1997-2, 918, aunque con las advertencias hechas supra n. 6; RODRÍGUEZ MOURULLO en: Rodríguez Mourullo (dir.), Comentarios, 1997, 561; MOLINA FERNÁNDEZ en: Bajo Fernández (dir.), Compendio PE II, 1998, 182; FARALDO CABANA, PJ 55, 1999, $52 \mathrm{~s}$.

37 HUERTA TOCILDO, Principales novedades, 1997, 70-74, mantiene que en el presente caso nos encontramos con una tipología de gravedad intermedia -aunque no una categoría intermedia- entre los delitos de omisión del deber de socorro (art. 195), denegación de auxilio (art. 412) y los delitos de homicidio y lesiones en comisión por omisión; en el mismo sentido, GOMEZ PAVON, PJ 40, 1995, 293 y 295; Tratamientos médicos, 1997, 308 y 309. Para CUADRADO RUIZ (La responsabilidad, 1998, 48) si hay un resultado, aunque éste sea de peligro concreto, estamos ante un delito de comisión por omisión; tb. FARALDO CABANA, PJ 55, 1999, 54.

38 Cfr. CARBONELl MATEU/GONZÁleZ CUSSAC en: Vives Antón (coord.), Comentarios I, 1996, 988; Vives Antón y otros, DP PE, 3.a, 1999, 280 s.; LANDECHO VELASCO/MOLINA BLAZQQUEZ, DP PE, 2.a 1996, 141; LOPEZ GARRIDO/GARCIA ARÁN, El Código penal, 1996, 114; PORTILLA CONTRERAS en: Cobo Del Rosal (dir.), Curso PE I, 1996, 385; ALMELA VICH, PJ 48, 1997, 252; hablando de una especie de párrafo cuarto del art. anterior (195), COBOS GOMEZ DE LINARES en: Rodríguez Ramos/Cobos Gómez/Sánchez Tomás, DP PE II, 1997, 25; MARTÍNEZ-PEREDA RODRIGUEZ, La responsabilidad penal, 3.a 1997, 388; APen 1997-2, 919, 921 y 922; GARCÍA ALBERO en: Quintero Olivares (dir.), Comentarios PE, 2.a 1 1999, 321; MUN̄OZ CONDE, DP PE, 12.a, 1999, 320 s. QUERALT JIMÉNEZ (DP PE, 3.a, 1996, 176), en cambio, parece no tomar partido al respecto y lo califica como un tipo emparentado con el delito de omisión del deber de socorro. 
ahí que no sea preciso que estén presentes los elementos básicos de la omisión del deber de socorro para que exista omisión de asistencia sanitaria ${ }^{39}$. En esta línea de interpretación HUERTA TOCILDO ${ }^{40}$ sostiene que los delitos sancionados por el art. 196 no constituyen un "plus» sino un "aliud" respecto del delito de omisión del deber de socorro, posición que defiende utilizando distintos argumentos: por un lado, porque el deber cuyo incumplimiento sanciona el delito de omisión del deber de socorro sólo surge cuando se tiene noticia de que una persona se encuentra desamparada y en peligro manifiesto y grave para su vida, su salud o su integridad física, en cambio, el tipo de los delitos de denegación de asistencia sanitaria y de abandono de servicios sanitarios incluye entre sus elementos la exigencia de que de dichas omisiones se derive un riesgo grave para la salud de las personas, riesgo que no puede ser preexistente a la emergencia del deber de actuar, como sucede en el delito de omisión del deber de socorro. No obstante ${ }^{41}$, reconoce, tampoco puede afirmarse en puridad que de la denegación de asistencia o del abandono de los servicios sanitarios se cree un riesgo grave que antes no existía; lo que sí puede producirse, como consecuencia de la omisión, es un empeoramiento de una dolencia anterior, o el empeoramiento de un proceso patológico preexistente que el omitente deja -con su omisión- que siga su curso natural, desembocando en un riesgo grave para la salud de la persona afectada, de tal manera que lo que se castiga es el no evitar, pudiendo hacerlo, que la enfermedad preexistente se agrave hasta tal punto ${ }^{42}$. Por otro lado, y como consecuencia de lo anterior, concluye que el deber de actuar contenido en el art. 196 tiene su origen en una situación típica distinta de aquella que incumbe a todos los ciudadanos, a lo que se le suma la especialidad en el círculo de autores posibles, conclusión ésta que le lleva a afirmar que estamos ante un delito autónomo e independiente del genérico delito de omisión del deber de socorro contenido en el precedente art. $195^{43}$.

\section{Bien Jurídico}

En cuanto al bien jurídico protegido también existen diversas opiniones, siendo la más extendida aquella que considera que los bienes jurídicos protegidos por el art. 196 no pueden ser otros que la vida, la salud e integridad física de las personas, en

39 Vid. GOMEZ PAVON, PJ 40, 1995, 298; Tratamientos médicos, 1997, 313; HUERTA TOCILDO, Principales novedades, 1997, 65 ss. y 103 s.; RODRfGUEZ MOURULLO en: Rodríguez Mourullo (dir.), Comentarios, 1997, 562; LÓPEZ BARJA DE QUIROGA en: Granados Pérez/López Barja, Contestaciones PE II, 1998, 151; MOLINA FERNÁNDEZ en: Bajo Fernández (dir.), Compendio PE II, 1998, 177 s.; FARALDO CABANA, PJ 55, 1999, $51 \mathrm{~s}$.

40. HUERTA TOCILDO, Principales novedades, 1997, 65 ss., y 103 s.

$41 \mathrm{Y}$ aquí recurre a los mismos argumentos que LUZÓN PEÑA (LL 1986-3, 543; PJ 2, 1986, 81; EPen, 1991, 237) urilizara para establecer diferencias entre los casos de comisión por omisión y aquellos constiturivos de una omisión pura.

42 En el mismo sentido, GOMEZ PAVÓN, PJ 40, 1995, 295; Tratamientos médicos, 1997, 310.

43 Cfr. HUERTA TOCILDO, Principales novedades, 1997, 65 ss., y 103 s. Con similares argumentos, los autores citados supra n. 39. 
cuanto puedan ser puestos en peligro por la denegación de asistencia o el abandono de los servicios sanitarios, excluyendo naturalmente, la lesión efectiva de los mismos ${ }^{44}$. La cuestión se complica cuando se relacionan los bienes jurídicos protegidos por el art. 196 y los protegidos por el delito de omisión del deber de socorro del art. 195, complicaciones que, por otro lado, son normales que surjan, si se parte de la base -errónea a nuestro juicio ${ }^{45}$ - de entender que el bien jurídico protegido por el art. 195 es, en general, la solidaridad humana ${ }^{46}$; además, y siempre relacionando los bienes jurídicos protegidos por ambos preceptos, encontramos posiciones que, de entrada, manifiestan que el bien jurídico protegido por el art. 196 es, también, la solidaridad humana, patentizada en el deber de asistir a una persona cuya vida e integridad física se encuentren en peligro ${ }^{47}$. Finalmente, no faltan quienes discrepando de las posturas anteriormente esbozadas entienden que, a través de este tipo penal lo que se trata de proteger son los deberes específicos que pesan sobre determinados profesionales ${ }^{48}$.

${ }^{44}$ Así, GOMEZ PAVÓN, PJ 40, 1995, 298; Tratamientos médicos, 1997, 313, en donde habla de los bienes jurídicos vida y salud de las personas; para GOMEZ RIVERO (LL 1996-3, 1387) se protege, no sólo la vida, sino de forma más amplia la salud de las personas; en sentido parecido, HUERTA TOCILDO, Principales novedades, 1997, 77 ss.; MOLINA FERNÁNDEZ en: Bajo Fernández (dir.), Compendio PE II, 1998, 178.

4s Sobre ello, cfr. mi tesis doctoral sobre el delito de omisión del deber de socorro, de próxima publicación.

46 En esta línea, GOMEZ PAVÓN, PJ 40, 1995, 298; Tratamientos médicos, 1997, 313, manteniendo que el bien jurídico protegido en ambos preceptos es diferente: en el primero (195) sería la solidaridad humana -aunque matizando que se protege ésta como medio necesario para la prosección de bienes jurídicos individuales como la vida y la salud-, en el segundo precepto (196), el interés protegido es directamente la vida y la salud de las personas; LÓPEZ BARJA DE QUIROGA/PÉREZ DEL VALLE en: CondePumpido Ferreiro (dir.), Código penal II, 1997, 2311, evitando pronunciarse sobre el bien jurídico protegido por el art. 196, se conforman con decir que "el deber cuya vigencia protege el art. $196 \mathrm{CP}$ no es un mero deber de solidaridad".

${ }^{47}$ Así, PORTILla CONTRERAS en: Cobo Del Rosal (dir.), Curso PE I, 1996, 386; en el mismo sentido, MORA ALARCÓN, Suma PG y E, 1996, 375. QUERALT JIMÉNEZ (DP PE, 3. a, 1996, 177), al considerar que el bien jurídico protegido por el art. 195 es la indemnidad de las personas, entiende que ese es el mismo bien jurídico que trata de proteger el art. 196, "indemnidad de las personas que integran la comunidad", añadiendo que éste debería ser considerado como un delito contra la salud pública y no contra las personas; sin embargo, HUERTA TOCILDO (Principales novedades, 1997, 88) se opone a la posición de Queralt Jiménez.

${ }^{48}$ De esta posición, ALMELA VICH (PJ 48, 1997, 252), al sostener que el bien jurídico protegido es, en primer lugar, el deber profesional $y$, en segundo, la salud de las personas; MARTÍNEZ-PEREDA RODRfGUEZ (APen 1997-2, 921), quien además de oponerse a que se tenga como bien jurídico la solidaridad humana, lleva la discusión al terreno de la cualificación del personal sanitario, argumentando que es ésta la que fundamenta la agravación; en el mismo sentido, RODRfGUEZ MOURULLO en: Rodríguez Mourullo (dir.), Comentarios, 1997, 560. En contra, GOMMEZ PAVÓN, PJ 40, 1995, 288; Tratamientos médicos, 1997, 303. 


\section{Tipo Objetivo: Requisitos}

\section{Sujetos}

En cuanto a los sujetos debemos decir que las conductas de denegación o abandono sólo pueden ser realizadas por un círculo determinado de sujetos; de ahí que también se lo considere como un delito especial impropio, en cuanto sólo pueden ser sujetos activos los profesionales de la sanidad ${ }^{49}$; no se trata pues, de un deber impuesto con carácter general, sino de un deber específico impuesto a los miembros de una actividad o profesión, en este caso, a los miembros de la profesión médica sanitaria ${ }^{50}$. No contento con esta reserva, el tipo penal restringe aún más el círculo de autores posibles, pues el sujeto activo, además de ser un profesional de la sanidad, debe estar obligado a la prestación de dicho servicio (elemento normativo); de esta manera sale al paso de dos cuestiones importantes: primero, de la posible colisión del deber contenido en el tipo con el derecho constitucional de huelga ${ }^{51}$, y segundo, del peligro que supondría la imposición de un deber de asistencia basado únicamente en el hecho de que el agente pertenezca a la profesión médica sanitaria. Pese a lo anterior, ello no significa que el profesional médico sanitario que no esté en servicio $y$, por tanto, no obligado conforme al art. 196, no cometa ningún delito si viendo en la calle (o en cualquier otro sitio que no sea su centro de trabajo, o que aun estando en él se encuentre fuera de servicio) a una persona herida o lesionada decide no prestarle la asistencia requerida y apropiada según las circunstancias del caso; por el contrario, si la persona se encuentra desamparada y en peligro manifiesto y grave, debemos afirmar la tipicidad conforme al delito de omisión del deber de socorro del art. 195 $\mathrm{CP}$, ya que en tal caso no está más obligado de lo que lo estaría cualquier persona; tampoco habría inconveniente en aplicar el delito de denegación de auxilio del art. 412. 3. $\mathrm{CP}$, siempre que el profesional sea funcionario ${ }^{52}$.

49 GÓMEZ PAVÓN, PJ 40, 1995, 289 ss.; Tratamientos médicos, 1997, 303 ss.; CARBONELL MATEU/ GONZALEZ CUSSAC en: Vives Antón (coord.), Comentarios I, 1996, 988; Vives Antón y otros, DP PE, 3.a, 1999, 281; COBOS GOMEZ DE LINARES en: Rodríguez Ramos/Cobos Gómez/Sánchez Tomás, DP PE I1, 1997, 25; MARTfNEZ-PEREDA RODRfGUEZ, La responsabilidad penal, 3.a , 1997, 390; APen 1997-2, 923; FARALDO CABANA, PJ 55, 1999, 60 s.; GARCfA ALBERO en: Quintero Olivares (dir.), Comentarios PE, 2.a 1999,322 ; MUNOZ CONDE, DP PE, 12." $, 1999,320$.

so GOMEZ PAVON, PJ 40, 1995, 289; Tratamientos médicos, 1997, 303.

si Al respecto, GOMMEZ RIVERO, LL 1996-3, 1387; LÓPEZ GARRIDO/GARCIA ARÁN, El Código penal, 1996, 114; ALMELA VICH, PJ 48, 1997, 253; HUERTA TOCILDO, Principales novedades, 1997, 79 s.; RODRIGUEZ MOURULLO en: Rodríguez Mourullo (dir.), Comentarios, 1997, 560; FARALDO CABANA, PJ 55, 1999, 60, n. 39; GARClA ALBERO en: Quintero Olivares (dir.), Comentarios PE, 2. ${ }^{a}, 1999,321$; MUNOZ CONDE, DP PE, 12. ${ }^{\text {a }}$ 1999, 321.

52 Opiniones similares mantienen, entre otros, CARBONELL MATEU/GONZÁLEZ CUSSAC en: Vives Antón (coord.), Comentarios I, 1996, 989; Vives Antón y otros, DP PE, 3. a, 1999, 281 s.; GOMEZ RIVERO, LL 1996-3, 1387; PORTILLA CONTRERAS en: Cobo Del Rosal (dir.), Curso PE 1, 1996, 388; HUERTA TOCILDO, Principales novedades, 1997, 79; LÓPEZ BARJA DE QUIROGA/PÉREZ DEL VALLE en: Conde-Pumpido Ferreiro (dir.), Código penal II, 1997, 2312; MARTINEZ-PEREDA RODRÍGUEZ, La responsabilidad penal, 3.a, 1997, 390 s.; APen 1997-2, 923 s. 
De las personas que pueden realizar este tipo penal ya mencionamos que son aquellos que estén obligados a ello, generalmente los médicos, pero también la regulación administrativa sanitaria establece que, en circunstancias determinadas, estas labores las pueden desempeñar el enfermero o auxiliar sanitario ${ }^{53}$; en cualquier caso debe tratarse de profesionales - para algunos es indiferente si se trata del sector público o del sector privado ${ }^{54}$ que desempeñen una labor sanitaria y no cualquier trabajador de un hospital, quedando excluidos, entre otros, tanto el personal administrativo como el personal de limpieza ${ }^{55}$. En cuanto al sujeto pasivo, sólo puede serlo la persona a quien se deniega la asistencia sanitaria o la que es objeto del abandono de los servicios sanitarios anteriormente prestados y de cuya denegación y abandono se deriva un riesgo grave para su salud.

\section{Conductas típicas}

En relación con la conducta típica debemos decir que ésta viene determinada por dos modalidades distintas: una de ellas consiste en denegar asistencia sanitaria, mientras que la otra precisa del abandono de determinados servicios sanitarios; en cualquier caso, es necesario que de ellas se derive un riesgo grave para la salud de las personas ${ }^{56}$. La primera conducta consiste en denegar la asistencia sanitaria que, atendidas

53 Al respecto, CARBONELL MATEU/GONZALLEZ CUSSAC en: Vives Antón (coord.), Comentarios I, 1996, 988; Vives Antón y otros, DP PE, 3.a. 1999, 281; QUERALT JIMÉNEZ, DP PE, 3.a, 1996, 176, añadiendo que además de los médicos, deben incluirse otros facultativos no médicos pero auxiliares de éstos en diagnósticos (biólogos, bioquímicos, físicos...) o dispensadores de sus tratamientos (farmacéuticos, protésicos), diplomados en enfermería, operadores de ciertas maquinarias, auxiliares de enfermería, conductores de ambulancia, celadores. En contra de la posición de Queralt Jiménez se manifiestan LÓPEZ BARJA DE QUIROGA/PÉREZ DEL VALLE en: Conde-Pumpido Ferreiro (dir.), Código penal II, 1997, 2308, n. 40, sobre todo al admitir como posibles sujetos activos a los celadores y a los conductores de ambulancia; en la misma línea de exclusión se manifiesta MOLINA FERNÁNDEZ en: Bajo Fernández (dir.), Compendio PE II, 1998, 178. Incluyendo a los celadores y conductores de ambulancia ALMELA VICH, PJ 48, 1997, 252.

54 Cfr. MARTINEZ-PEREDA RODRIGUEZ, La responsabilidad penal, 3.a , 1997, 391; APen 1997-2, 924; MOLINA FERNÁNDEZ en: Bajo Fernández (dir.), Compendio PE II, 1998, 178. En contra de incluir como posibles sujetos activos de este delito a los profesionales de la sanidad que ejercen libremente su profesión, se muestra RODRIGUEZ MOURULLO en: Rodríguez Mourullo (dir.), Comentarios, 1997, 560; en el mismo sentido, en la doctrina italiana, CHIODI, RItML 1980, 264 s.; BONELLI/ GIANNELII, RITML 1992,774 ss.

ss Así, QUERALT JIMÉNEZ, DP PE, 3.a, 1996, 176.

56 Cfr. CARBONELL MATEU/GONZÁLEZ CUSSAC en: Vives Antón (coord.), Comentarios I, 1996, 988; Vives Antón y otros, DP PE, 3.a , 1999, 281; GÓMEZ RIVERO, LL 1996-3, 1387, que además explica que el tipo se configura mediante la técnica de los tipos mixtos, en el que la descripción de la conducta tiene lugar de un doble modo: bien mediante la denegación de la asistencia sanitaria, bien mediante el abandono de dichos servicios; PORTILLA CONTRERAS en: Cobo Del Rosal (dir.), Curso PE 1, 1996, 388; para QUERALT JIMÉNEZ, DP PE, 3.², 1996, 177, se trata de dos comportamientos alternativos: abandono y denegación, añadiendo que con el primero hubiera sido suficiente; en el sentido del texto, ALMELA VICH, PJ 48, 1997, 253; MARTINEZ-PEREDA RODRIGUEZ, La responsabilidad penal, 3. , 1997, 392; APen 1997-2, 925; RODRIGUEZ MOURULLO en: Rodríguez Mourullo (dir.), Comentarios, 1997, 561; FARALDO CABANA, PJ 55, 1999, 61 s., "se trata de un tipo mixto alternativo..., las dos modalidades de acción son necesarias"; GARCÍA ALBERO en: Quintero Olivares (dir.), Comentarios, 2.a 1999, 321 s.; MUNOZZ CONDE, DP PE, 12.a, 1999, 320. 
las circunstancias del caso concreto, fuera necesaria para solventar una situación de riesgo para la vida, la salud o la integridad física de las personas, y comprende, por tanto, el mantenerse pasivo ante la situación de necesidad, omitiendo los cuidados precisos, es decir, no conceder lo que se pide o solicita ${ }^{57}$; para algún autor incluso, el tipo también incluye como una forma de denegación aquella asistencia prestada de forma insuficiente (siempre que el riesgo marginal siga siendo grave ${ }^{58}$; en cualquier caso, se requiere que previamente a la denegación por parte del profesional se le haya solicitado, por el afectado o por un tercero, la prestación de sus servicios facultativos, solicitud que debe ser expresa o tácita, pero, en todo caso, perceptible por signos externos $^{59}$, y lo mismo sucede con el acto de la denegación, bastando con la omisión "consciente" del acto debido, sin que se requiera una manifestación expresa ${ }^{60}$. Finalmente, en cuanto a esta primera modalidad, hay que decir que por asistencia sanitaria debe entenderse la necesaria para el diagnóstico y tratamiento de las enfermedades y la conservación de la salud realizada conforme a las reglas de la ciencia médica (lex artis), debiendo tomar en cuenta, además, las circunstancias del caso concreto, es decir, la magnitud y gravedad de los padecimientos, sin olvidar las propias capacidades del profesional y del centro sanitario donde éste presta sus servicios ${ }^{61}$.

La segunda modalidad consiste en el cese o abandono en la prestación de unos servicios sanitarios determinados; de ahí que algunos autores opinen que se trata de una conducta activa (abandonar) ${ }^{62}$; sin embargo, para MOLINA FERNÁNDEZ ${ }^{63}$, la conducta típica no se configura con el mero acto de abandonar al paciente, sino por el hecho de que ese abandono determina que ante el surgimiento de una situación

57 Realizando una interpretación gramatical del precepto, GÓMEZ PAVON, PJ 40, 1995, 291; Tratamientos médicos, 1997, 305 .

58 MOLINA FERNÁNDEZ en: Bajo Fernández (dir.), Compendio PE II, 1998, 179.

5) Así, PORTilla CONTRERAS en: Cobo Del Rosal (dir.), Curso PE 1, 1996, 389; MARTfNEZPEREDA RODRIGUEZ, La responsabilidad penal, 3.a 1997, 392; APen 1997-2, 925; MOLINA FERNÁNDEZ en: Bajo Fernández (dir.), Compendio PE II, 1998, 179 ss.; GARCIA ALBERO en: Quintero Olivares (dir.), Comentarios PE, 2. $, 1999,321 \mathrm{~s}$. Restringiendo la conducta a aquellos casos de expreso requerimiento, HUERTA TOCILDO, Principales novedades, 1997, 89 ss.; tb. parece ser partidaria del requerimiento expreso, FARALDO CABANA, PJ 55, 1999, 58: "la denegación de asistencia constituye, precisamente, un supuesto de rechazo de asunción del paciente que de forma expresa solicita la intervención del profesional en su calidad de tal" (añadimos cursiva).

(w) Cfr. PORTILla CONTRERAS en: Cobo Del Rosal (dir.), Curso PE I, 1996, 388 s.; MARTINEZPEREDA RODRIGUEZ, La responsabilidad penal, 3.a, 1997, 392 s.; APen 1997-2, 926, con cita de algunas resoluciones del TS; RODRÍGUEZ MOURULLO en: Rodriguez Mourullo (dir.), Comentarios, 1997,561 .

(1) En este sentido, MOLINA FERNÁNDEZ en: Bajo Fernández (dir.), Compendio PE II, 1998, 180.

62 Cfr. COBOS GOMEZ DE LINARES en: Rodríguez Ramos/Cobos Gómez/Sánchez Tomás, DP PE II, 1997, 24; MARTINEZ-PEREDA RODRIGUEZ, La responsabilidad penal, 3. a, 1997, 393; APen $1997-2,926$.

63 MOLINA FERNÁNDEZ en: Bajo Fernández (dir.), Compendio PE II, 1998, 181. 
de necesidad sea imposible la prestación del servicio en el momento requerido, y ello porque en la mayoría de los casos el paciente se encuentra desprovisto de la atención facultativa que antes tenía, de tal manera que es en ese momento en el que se produce el -resultado- riesgo grave para su salud, siendo éste imputable al acto previo del abandono, configurando el tipo como una omissio libera in causa.

\section{Riesgo grave}

Ya hemos mencionado que buena parte de la doctrina, conforme con la regulación legal, requiere para afirmar la tipicidad de las conductas de denegación de asistencia y abandono de los servicios sanitarios que, a consecuencia de ello, se derive un riesgo grave para la salud de las personas; para RODRÍGUEZ MOURULLO ${ }^{64}$, lo que la ley castiga aquí es que el profesional sanitario, con su inasistencia o abandono, no haya modificado el curso de la dolencia y haya dado lugar así a que se produzca para la salud de la persona «un riesgo grave»; pero la opinión de que para afirmar la tipicidad del delito en cuestión es necesario que se produzca el resultado de peligro concreto equivale, como ya lo apuntó GOMEZ PAVÓN ${ }^{65}$, a dejar la tipicidad de la conducta en manos del azar; de forma tal que la conducta sería atípica si pese a haberse dado la denegación de la asistencia o el abandono de los servicios, no se produce un riesgo grave para la salud de las personas, y lo mismo sucederá si el riesgo sobrevenido tiene el carácter de leve ${ }^{66}$. Como ha señalado LUZÓN $\mathrm{PENA}^{67}$, lo anterior tendría sentido si la producción de un riesgo grave para la salud de las personas constituyera un elemento cualificante de un delito base, que no existe, es decir, si se tratara de un delito cualificado por el resultado, o si se entendiera que el riesgo grave es una condición objetiva de punibilidad, como no se trata ni de uno ni de otro, en todos aquellos casos en que el resultado de peligro concreto no llegue a producirse pese a que el agente ha permanecido 'inactivo' -ha denegado la asistencia o ha abandonado los servicios-, $y$, consecuentemente, ha ejecutado todos o parte de los actos que objetivamente deberían producir el resultado, lo que no se dará es el delito consumado, pero sí cabe la tentativa (con dolo directo o eventual), como recientemente lo ha apuntado también FARALDO CABANA ${ }^{68}$.

${ }^{64}$ RODRfGUEZ MOURULLO en: Rodriguez Mourullo (dir.), Comentarios, 1997, 561.

is GOMEZ PAVÓN, PJ 40, 1995, 294; Tratamientos médicos, 1997, 309.

${ }_{66}$ Para quienes opinan así, esto no significa que no puedan darse responsabilidades disciplinarias conforme a las normas administrativas y deontológicas; así lo sostienen p.ej. CARBONELL MATEU/GONZÁLEZ CUSSAC en: Vives Antón (coord.), Comentarios I, 1996, 989; Vives Antón y otros, DP PE, 3.a , 1999, 282; GÓMEZ RIVERO, LL 1996-3, 1387; PORTILLA CONTRERAS en: Cobo Del Rosal (dir.), Curso PE I, 1996, 388; ALMELA VICH, PJ 48, 1997, 254; MARTINEZ-PEREDA RODRÍGUEZ, La responsabilidad penal, 3.2, 1997, 391; APen 1997-2, $924 \mathrm{~s}$.

67 En sus explicaciones de Cátedra, curso 1999/2000.

68 Cfr. FARALDO CABANA, PJ 55, 1999, 59 s,, 69, si bien reconoce que, al no producirse siquiera el peligro para la salud de las personas, habrá poco interés del Ministerio Fiscal y de la parte afectada en promover la persecución de este delito, a lo que se le suma, que la pena que habría de imponerse es "realmente ridícula"; por ello, sostiene, quizá las sanciones colegiales y administrativas -algunas de ellas, la separación del servicio p.ej., más graves que la sanción impuesta por los arts. 196 y 412.3 CP- resulten más adecuadas, entendemos que desde el punto de vista preventivo -general y especial-. 
Por riego grave ha de entenderse -en palabras de GOMEZ PAVÓN ${ }^{69}$-, aquel que pone en peligro de forma relevante la salud o la vida de una persona, suponiendo un empeoramiento del estado de salud del paciente, llegando a afectar el normal funcionamiento de órganos o miembros importantes ${ }^{70}$; en todo caso, la calificación de un riesgo como grave constituye un elemento valorativo que deberá ser apreciado por el juez atendiendo las circunstancias del caso concreto ${ }^{71}$. En esta línea de interpretación, MOLINA FERNÁNDEZ ${ }^{72}$ cree que es necesario distinguir este resultado de peligro de la previa situación de peligro en la que se deniega la asistencia o se abandona el servicio, tratándose en ambos casos de un juicio de pronóstico cuyos elementos varían según que el peligro que genera la obligación de asistencia o permanencia se mida ex ante, en el momento que nace el deber, o ex post, es decir, examinando los efectos de la omisión en la situación previa de riesgo; en este sentido -añade-, para la imputación objetiva es imprescindible que dicho resultado sea concreción del riego inherente a la situación previa en la que el sujeto omite ${ }^{73}$.

Para GARCÍA ALBERO ${ }^{74}$, la trascendencia de exigir que de la denegación o abandono se derive un "riesgo grave para la salud de las personas", está en que esta conducta típica limita el ámbito de previsión típica a la asistencia sanitaria urgente y necesaria, lo que traducido a la práctica significa que generalmente la responsabilidad recaerá sobre facultativos de "urgencias" o de "guardia", o sobre determinados médicos, como los rurales, que se encuentran en la llamada "posición de monopolio de ayuda"75.

6.) GOMEZ PAVON, PJ 40, 1995, 296; Tratamientos médicos, 1997, 311.

7" En el mismo sentido, CARBONELL MATEU/GONZÁLEZ CUSSAC en: Vives Antón (coord.), Comentarios I, 1996, 989; Vives Antón y otros, DP PE, 3.a 1999, 282, para los que el "riesgo grave", va referido a la trascendencia o importancia para la salud de las personas, incluyendo el riesgo para la vida y para la integridad; en la misma línea, ALMELA VICH, PJ 48, 1997, 254. En contra de que el tipo penal contenido en el art. 196 incluya un peligro grave para la vida, HUERTA TOCILDO, Principales novedades, 1997,92, n. 52.

${ }^{11}$ Así, con este razonamiento, GOMEZ RIVERO, LL 1996-3, 1387. Sobre los diferentes grados de valoración del riesgo cfr. MUÑOZ CONDE, DP PE, 12.a, 1999, $320 \mathrm{~s}$.

72 Cfr. MOLINA FERNÁNDEZ en: Bajo Fernández (dir.), Compendio PE II, 1998, $181 \mathrm{s.}$

73 Para RODRÍGUez MOURUllo (en: Rodriguez Mourullo (dir.), Comentarios, 1997, 561), el hecho de que el tipo vincule expresamente la conducta del profesional (denegación o abandono) con el imperativo de que de ella se derive un riesgo grave, obliga a operar con los criterios propios de la causalidad e imputación objetiva. En relación con los problemas que plantea la imputación del resultado y la inviabilidad de la causalidad hipotética, cfr. GÓMEZ PAVÓN, PJ 40, 1995, 303 s.; Tratamientos médicos, 1997, 318 s.

74 GARCÍA ALBERO en: Quintero Olivares (dir.), Comentarios PE, 2.a, 1999, 322 (las comillas del texto se corresponden con las.del original)

75 Sobre la llamada posición de monopolio de ayuda vid., SILVA SÁNCHEZ, LL 1987-1, 958; tb. en: Mir Puig (edir.), Avances, 1988, 130. 


\section{Parte Subjetiva del Tipo}

En el aspecto subjetivo del tipo, estamos ante un tipo doloso, la realización imprudente del mismo es, en consecuencia, impune al no estar expresamente tipificada ${ }^{76}$. Por otro lado, si el dolo es "conocimiento y voluntad de realizar todos los elementos objetivos del tipo total de injusto"77, en el delito en estudio éste-el dolo- debe abarcar, además del conocimiento -pleno o más o menos aproximado- de la situación generadora del deber, la voluntad de omitir (denegando la asistencia solicitada o abandonando la prestación del servicio) la realización de la acción que de acuerdo a las circunstancias y conforme a la lex artis se requería; conocimiento y voluntad -siquiera eventual- que ha de abarcar también, en tanto elemento del tipo, al resultado de peligro concreto: el riesgo grave para la salud de las personas.

En cualquier caso, deben tenerse presente que aquí, al igual que sucede en el delito de omisión del deber de socorro, pueden presentarse casos de error -vencible o invencible- sobre todo en lo que respecta al resultado; así, en aquellos casos en los que el médico desconoce -pudiendo y debiendo conocer si actuara con la diligencia debida- que de la denegación o del abandono de los servicios puede producirse una situación de grave riesgo para el paciente ${ }^{78}$.

Finalmente, no queremos dejar de apuntar que la existencia de este delito constituye un límite legal a la cláusula general de los delitos de omisión impropia contenida en el art. $11 \mathrm{CP}$, pues abarca casos en donde la eventual posición de garante del personal médico sanitario, sea por imperativo legal (ley), sea por asunción voluntaria (contrato), no configuran un delito de comisión por omisión ${ }^{79}$.

76 Cfr. LANDECHO VELASCO/MOLINA BLÁZQUEZ, DP PE, 2.", 1996, 141; MORA ALARCÓN, Suma PG y E, 1996, 374; PORTILLA CONTRERAS en: Cobo Del Rosal (dir.), Curso PE I, 1996, 389 s.; HUERTA TOCILDO, Principales novedades, 1997, 94; MARTÍNEZ-PEREDA RODRÍGUEZ, La responsabilidad penal, 3.a, 1997, 393 s.; APen 1997-2, 926.

7 Así, LUZÓN PEÑA, Curso PG I, 1996, 405.

${ }^{78}$ Cfr. FARALDO CABANA, PJ 55, 1999, $62 \mathrm{~s}$.

79 Sobre ello, cfr. SILVA SÁNCHEZ, El nuevo Código penal, 1997, 72 ss.; MOLINA FERNÁNDEZ en: Bajo Fernández (dir.), Compendio PE II, 1998, 182 ss. 


\section{Consideración Personal}

Como hemos podido observar, el legislador de 1995 ha optado por conceder a este tipo penal una tipología compleja, que alejándose en gran medida de los delitos de omisión pura se acerca, por no decir constituye, a los llamados delitos de comisión por omisión. Quizá lo apropiado hubiera sido no mencionar el hecho que de la omisión o del abandono de tales servicios "se derive un riesgo grave para la salud de las personas", pues a los problemas dogmáticos que tal construcción acarrea, se le suman áquellos de carácter probatorio anudados a la producción de un riesgo grave para la salud de las personas; por ello creemos que el tipo penal debía conformarse con que la mencionada omisión o el abandono de los servicios sea realizado por el personal obligado a la prestación de los mismos, configurando de esta manera, y por esta circunstancia, un tipo agravado del delito de omisión del deber de socorro como una expresión más de los llamados por SILVA SÁNCHEZ, delitos de omisión pura de garante ${ }^{80}$; salvando al mismo tiempo la discusión sobre la pretendida autonomía del tipo penal respecto del tipo genérico del art. $195 \mathrm{CP}$, y dejando solamente la posibilidad de discutir sobre el bien jurídico protegido, discusión que en nuestro caso, carece de sentido en cuanto, para nosotros, ambas figuras, con las especialidades propias de cada caso, es decir, las referidas al sujeto activo, protegen el mismo bien jurídico (las expectativas de conservación y aseguramiento de la vida e integridad física), idea ésta favorecida, además, por el hecho de que los preceptos en cuestión se encuentran bajo una misma rúbrica, sin olvidar que si tomamos en cuenta la redacción de la que han sido dotados, uno (196) constituye un tipo cualificado -agravadorespecto al otro (195).

Por otro lado, en cuanto a la concurrencia o no de los requisitos establecidos por el art. 195 -nos referimos a la existencia de una persona desamparada y en peligro manifiesto y grave-, creemos que en el caso del art. 196, su concurrencia puede

8i: De la misma opinión es GOMEZ PAVÓN, PJ 40, 1995, 294; Tratamientos médicos, 1997, 309; tb. HUERTA TOCILDO (Principales novedades, 1997, 107 ss.), aunque expone que tal construcción no estaría exenta de inconvenientes, al tener que partir necesariamente de la preexistencia de un peligro manifiesto y grave para la vida, la integridad física o la salud de una persona desamparada, concluyendo que esto sería una construcción político-criminalmente indeseable, a menos que se desvincule por completo del delito de omisión del deber de socorro, proponiendo en consecuencia una posterior reforma de este delito que albergue tanto la modalidad de omisión pura de garante como la de omisión y resultado - de peligro concreto- con el siguiente tenor:

"El profesional que, estando obligado a prestarla, denegare asistencia sanitaria, o abandonare los servicios sanitarios a su cargo, será castigado con la pena de multa de seis a doce meses y con la de inhabilitación especial para el empleo o cargo público, profesión u oficio, por tiempo de seis meses a dos años.

Cuando de la denegación o abandono se derive un incremento de un riesgo preexistente para la vida o la salud de la persona desasistida, se le impondrá la pena de multa de doce a dieciocho meses y la de inhabilitación especial por tiempo de uno a tres años". 
funcionar, al igual que lo hace en el art. 195, como una especie de límite que obliga a descartar la existencia del delito en enfermedades o padecimientos leves o que, aun siendo graves, no colocan a la persona que los sufre en una situación de desamparo que requiera una asistencia inmediata, teniendo siempre la posibilidad de recurrir a otro centro sanitario o a un centro médico más calificado para atender la dolencia que le aqueja ${ }^{81}$; por el contrario, caen dentro del tipo todas aquellos casos que por la situación de la víctima requieren una atención inmediata, es decir, casos en los que la víctima, en la situación concreta, frente al omitente, se encuentra desamparada, en cuanto no puede prestarse ayuda a sí misma, ni cuenta con nadie que, dadas las circunstancias del caso, le preste la ayuda necesaria, y es una persona que al mismo tiempo se encuentra ante un peligro manifiesto y grave, que amenaza su vida, su integridad física y por tanto su salud.

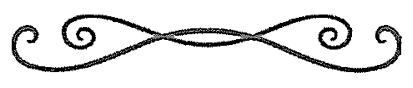

81 Piénsese p.ej. en enfermedades tan graves como el cáncer, o el SIDA. 